\title{
A re-evaluation of sperm protein 17 (Sp17) indicates a regulatory role in an A-kinase anchoring protein complex, rather than a unique role in sperm-zona pellucida binding
}

\author{
J. Frayne and L. Hall* \\ Department of Biochemistry, University of Bristol, School of Medical Sciences, Bristol, UK
}

\begin{abstract}
Sp17 was originally proposed to be a sperm-specific protein and thought to play a role in sperm-egg interactions by binding to the zona pellucida via two conserved heparin-binding motifs. However, more recent data indicate that it may be expressed more widely, both in tumours and in normal somatic tissues. The complete nucleotide and deduced amino acid sequences of human Sp17 transcripts are reported and it is shown that they are
\end{abstract}

expressed in a wide range of tissues, albeit at a much lower expression than in the testis. On the basis of the extremely high sequence conservation throughout the $\mathrm{N}$-terminal half of Sp17, and the presence within this region of an A-kinase anchoring protein (AKAP)-binding motif, it is postulated that the proposed role of Sp17 in zona pellucida binding is unlikely to be its principal function.

\section{Introduction}

Sperm protein 17 (Sp17) was originally isolated as a member of the rabbit sperm-specific autoantigen (RSA) family, antibodies to which impede fertilization both in vitro and in vivo (O'Rand, 1981; O'Rand et al., 1984). Subsequently, Sp17 has been detected in every mammalian species examined and its transcripts have been reported, on the basis of northern blot analysis, to be exclusively expressed in the testis (Richardson et al., 1994; Adoyo et al., 1997). A primary role for Sp17 in binding to the extracellular matrix of the oocyte was originally postulated, by virtue of its ability to bind both to heat-solubilized zona pellucida and sulphated complex carbohydrates (Richardson et al., 1994). This hypothesis was further reinforced by the observation that transfected COS cells expressing recombinant Sp17 showed punctate binding of zona pellucida on their surface (Yamasaki et al., 1995), implying association with Sp17, despite the fact that Sp17 lacks a signal peptide or recognizable transmembrane domain. Indeed, Sp17 is not expressed on the sperm surface, but is localized within the cytoplasm of the sperm head and throughout the tail regions (Richardson et al; 1994; Kong et al., 1995; Adoyo et al., 1997). Moreover, protein in the sperm head is inaccessible to antibody recognition until after initiation of the acrosome reaction (Richardson et al., 1994; Kong et al., 1995). Nevertheless, Sp17 has been proposed as an immunocontraceptive target antigen (Lea et al., 1998a,b), although preliminary immunization studies with this protein do not show consistent effects on fertility (Lea et al., 1998b).

Transcripts for Sp17 have been cloned and sequenced

*Correspondence

Email: L.Hall@bristol.ac.uk from a wide range of mammalian species including rabbits, mice, rats, humans, macaques, baboons and sheep and are found to be highly conserved. Analysis of the primary amino acid sequence of Sp17 shows that the protein has several interesting features. In particular, the first 74 amino acid residues are almost totally conserved among all species studied and contain a region that shows striking sequence similarity to the $\mathrm{N}$-terminus of the CAMP-dependent protein kinase A regulatory subunit II (PKA RII), which is essential for protein dimerization and interaction with A-kinase anchoring proteins (AKAPs).

In addition, Sp17 contains two conserved heparinbinding motifs that have been shown to interact with heparin in vitro with very high affinity (Wen et al., 2001), which undoubtedly accounts for the ability of Sp17 to interact with zona pellucida proteins. Finally, Sp17 also contains a C-terminal calmodulin-binding motif that has been shown to interact with calmodulin in vitro (Wen et al., 1999). As the C-terminus of Sp17 is cleaved, either in vitro by trypsin, or during the acrosome reaction, it has been proposed that such cleavage could release free calmodulin that could then modulate downstream signalling pathways (Wen et al., 1999). However, as only a very small proportion of native Sp17 appears to be cleaved during the acrosome reaction, the proposed change in free calmodulin concentration is unlikely to be physiologically significant (Wen et al., 1999).

Although originally shown to be exclusively expressed in the testis by northern blot analysis, a number of more recent reverse transcriptase-polymerase chain reaction (RT-PCR)based studies have described the aberrant expression of Sp17 transcripts in tumour cells from patients with multiple myeloma and ovarian carcinoma, and in myeloma cell lines (Lacy and Sanderson, 2001; Lim et al., 2001; ChirivaInternati et al., 2002). Moreover, Sp17 protein has been 
detected in such cells by western blot analysis with Sp17specific antisera, leading to the suggestion that Sp17 is a cancer-testis (CT) antigen. CT antigens constitute a group of proteins that are normally testis-specific (Old and Chen, 1998), but are expressed aberrantly in tumour cells; their immunogenicity and restricted tissue localization make them candidates for immunotherapy. The reason for their atypical expression in tumour cells is most likely related to genetic hypomethylation, a feature common to malignant cells and testicular germ cells.

Aberrant expression of Sp17 in tumour cells would not be inconsistent with its originally reported testis-specific expression in normal cells. However, a recent study in mice reports the expression of Sp17 in normal somatic cells from a wide range of tissues by RT-PCR analysis (Wen et al., 2001); this finding is in direct contrast to a separate study, also using RT-PCR, that examined the expression of Sp17 in a range of human tissues and concluded that Sp17 was expressed solely in the testis (Lim et al., 2001).

In the present study the tissue localization of Sp17 transcripts in rats, macaques (Macaca fascicularis) and humans is investigated, and their expression in a wide range of tissues in addition to the testis is described. In light of new information, which has been reported for Sp17 in recent years, the potential role of this very highly conserved protein in cell function is re-addressed.

\section{Materials and Methods}

Reverse transcriptase-polymerase chain reaction ( $R T-P C R$ )

Human testis total RNA was obtained from Clontech Labs (Palto Alto, CA). Rat and macaque (Macaca fascicularis) total RNA was prepared from a variety of tissues using a TRIzol ${ }^{\circledR}$-based method, as described by Frayne et al. (1997). Total RNA $(2 \mu \mathrm{g})$ was used as a template for oligo(dT) ${ }_{12-18}$-primed Expand ${ }^{\mathrm{TM}}$ (Roche, Lewes) reverse-transcriptase-directed cDNA synthesis using buffer and conditions supplied by the manufacturer. Aliquots of this cDNA were then used with appropriate primers in 30-cycle PCR reactions using the Expand ${ }^{\mathrm{TM}}$ High Fidelity PCR system (Roche) with the following cycle parameters: denaturation at $94^{\circ} \mathrm{C}$ for $1 \mathrm{~min}$, annealing at $58^{\circ} \mathrm{C}$ for $1.5 \mathrm{~min}$, extension at $72^{\circ} \mathrm{C}$ for $1 \mathrm{~min}$. For human tissue distributions, cDNA for a range of tissues was purchased from Clontech Labs and used in PCR reactions under the same conditions as above.

\section{5' Rapid amplification of CDNA ends (RACE)}

The $5^{\prime}$ end of the human Sp17 transcript was obtained from testis total RNA using a SMART'M RACE CDNA amplification kit from Clontech Labs, essentially as described by the supplier. Briefly, first-strand cDNA synthesis was performed using human testis total RNA $(2 \mu \mathrm{g})$, the $5^{\prime}$-CDS primer and SMART II ${ }^{\mathrm{TM}}$ oligonucleotide (both provided in the RACE kit) and SuperScript ${ }^{\mathrm{TM}}$ II reverse transcriptase (Gibco-BRL, Paisley). This cDNA was then used in a PCR reaction with the upstream primer mix (included in the RACE kit) and an Sp17-specific reverse primer (either 5'-CAGGTGGTTCTTGCTCCTCGAATGCATG-3' (reverse primer A) or 5'-GTTATAGAAGCGGTCTTCTACCTTACTC$3^{\prime}$ (reverse primer B)) using the Advantage ${ }^{\circledR} 2$ PCR kit from Clontech Labs with the following touchdown parameters: $5 \mathrm{~s}$ at $94^{\circ} \mathrm{C}, 3 \mathrm{~min}$ at $72^{\circ} \mathrm{C}$ for five cycles; then $5 \mathrm{~s}$ at $94^{\circ} \mathrm{C}, 10 \mathrm{~s}$ at $70^{\circ} \mathrm{C}, 3 \mathrm{~min}$ at $72^{\circ} \mathrm{C}$ for five cycles; then $5 \mathrm{~s}$ at $94^{\circ} \mathrm{C}, 10 \mathrm{~s}$ at $68^{\circ} \mathrm{C}, 3 \mathrm{~min}$ at $72^{\circ} \mathrm{C}$ for 25 cycles. The resulting PCR products were resolved on a low-melting-temperature agarose gel and the appropriate bands excised and sequenced directly using an $\mathrm{ABI} 377$ automated sequencer (Applied Biosystems, Warrington).

\section{Results}

\section{Determination of the sequence of human Sp17 cDNA}

Human Sp17 has been reported by Lea et al. (1996) to be encoded by two alternative transcripts $(1.3 \mathrm{~kb}$ and $1.6 \mathrm{~kb})$ with identical coding regions but differing in the length and sequences of their 5' non-coding regions. These authors proposed that these may arise by alternative splicing, as preliminary Southern blot analyses suggested that the human genome contains only a single Sp17 gene. Furthermore, the two alternative human Sp17 5' non-coding regions contain multiple ATG codons, a feature that is unusual in this region of eukaryotic transcripts. Database searches with the two $5^{\prime}$ non-coding regions were carried out and one that was almost identical (98.2\% identity) to part of a human ATP-dependent RNA helicase transcript (accession number: AF214731) and the other $(99.4 \%$ identity) to a human transmembrane phosphatase with tensin homology (accession number: XM012295) were found. It therefore appears that each of these previously reported human Sp17 sequences, which were isolated from a commercial cDNA library (Clontech Labs), represent fused clones.

The authentic sequence of human Sp17 cDNA was established by first confirming that the sequence of the entire coding region (which was virtually identical to that of baboons (accession number: U75209) and macaques (accession number: AF005551) Sp17 cDNA) by PCR, using primers (5'-GTTCCATAGGCAGTTCTTACC-3' and 5'TGGAGGTAAAACCAGTGTCCT-3') that immediately flanked the coding region. Subsequent ABI 377 automated sequence analysis of the cloned 503bp PCR product (nucleotides 52-554 in Fig. 1) indicated that it was identical to the corresponding region published by Lea et al. (1996).

The 5' non-coding region of the human Sp17 transcript was then determined by rapid amplification of cDNA ends (RACE) using a commercially available SMARTTM RACE CDNA amplification kit and two alternative, gene-specific, reverse primers from within the sequenced coding region. In each case, a single major amplicon was obtained, representing reverse transcription to the predominant transcriptional start site. The amplified fragments (364 bp and $333 \mathrm{bp}$, 


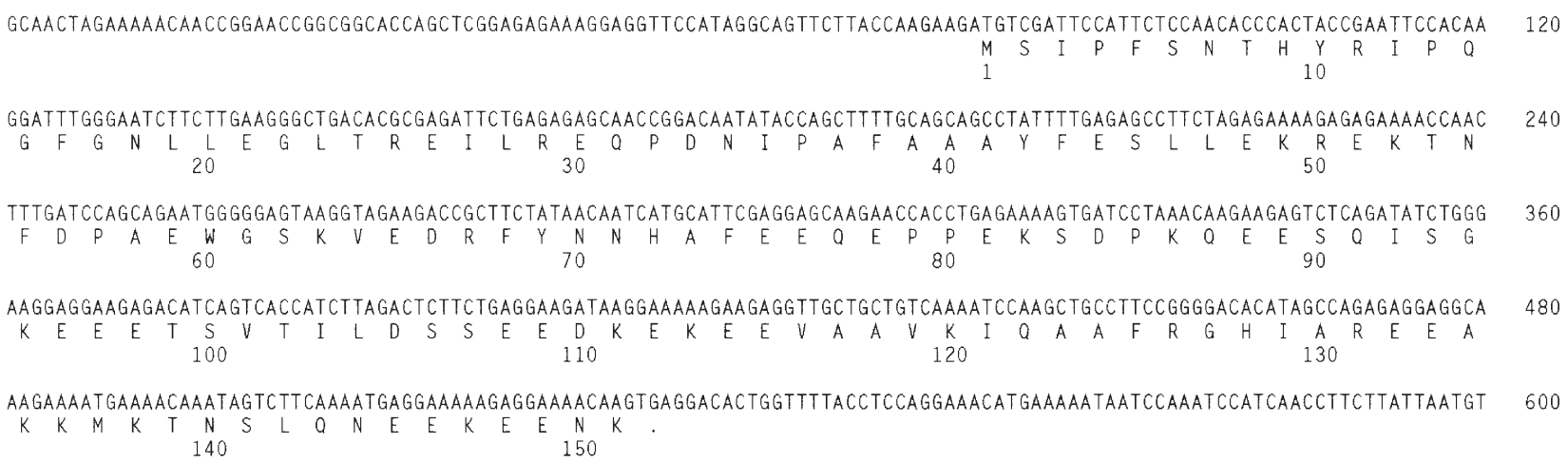

Fig. 1. Complete nucleotide and deduced amino acid sequence of human Sp17 cDNA.

including the 5' RACE primer; Fig. 2) were then sequenced directly and constitute nucleotides 1-319 and 1-288, respectively (Fig. 1). Comparison with the corresponding $5^{\prime}$ non-coding sequence of baboon Sp17 cDNA revealed that the human 5' sequence depicted (Fig. 1) contains one fewer nucleotide and exhibits $96 \%$ sequence identity, confirming that this is the authentic $5^{\prime}$ non-coding region of human Sp17. A recent, unpublished cDNA sequence for human Sp17 (accession number: AF334735) contains a 5' noncoding region that contains 57 more nucleotides than that reported here, although the two sequences are identical in the region common to both. This putative longer transcript, which contains an unusual oligo $(\mathrm{dT})_{14}$ tract, presumably represents expression from a rarely used alternative transcriptional start site, since 5' RACE (Fig. 2) revealed only a single major start site producing the transcript depicted (Fig. 1). The use of alternative transcriptional start sites is not unexpected, as the human Sp17 gene (accession number: I3640260) lacks a recognizable TATA box promoter element, a feature that is frequently associated with multiple initiation sites.

For completeness, the entire $3^{\prime}$ non-coding region of the human Sp17 transcript was amplified by RT-PCR, using a forward primer derived from within the coding region and a reverse primer based on the human genomic (I3640260) and unpublished (AF334735) Sp17 cDNA sequences. This 3' non-coding amplicon was sequenced directly and is also shown (Fig. 1).

\section{Tissue distribution of Sp17 transcripts}

Although Sp17 has frequently been reported to be expressed exclusively in the testis, transcripts have recently been detected by RT-PCR in a range of murine somatic tissues (Wen et al., 2001), albeit in much lower amounts

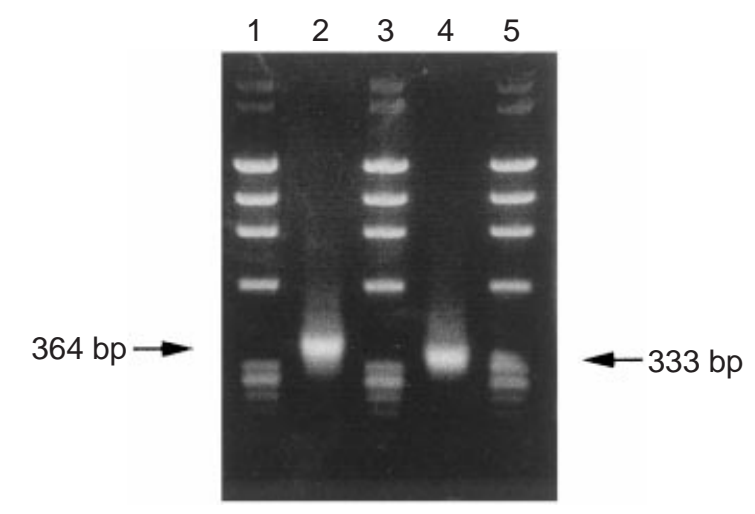

Fig. 2. 5' Rapid amplification of cDNA ends (5'-RACE) of human Sp17 transcripts. The $5^{\prime}$ non-coding region of human Sp17 transcripts was amplified by RACE and the resulting products were analysed by agarose gel electrophoresis in the presence of ethidium bromide. Lanes 1, 3 and 5: DNA size markers; lanes 2 and 4: PCR products obtained using a generic forward primer and Sp17-specific, reverse primer A (5'-CAGGTGGTTCTTGCTCCTCGAATGCATG-3') or B (5'-GTTATAGAAGCGGTCTTCTACCTTACTC-3'), respectively.

when compared with testis. Somewhat surprisingly, using a similar approach, Lim et al. (2001) failed to detect Sp17 transcripts in any human tissues other than testis. Therefore, it was decided to re-establish whether Sp17 was expressed in human somatic tissues.

A panel of human cDNAs (brain, heart, kidney, liver, lung, pancreas, placenta, skeletal muscle and testis) was obtained from Clontech Labs and used in PCR reactions with Sp17-specific primers. Parallel control reactions were performed on all cDNA preparations using glyceraldehyde3-phosphate dehydrogenase-specific primers to check the integrity and concentration of each cDNA. 
(a)

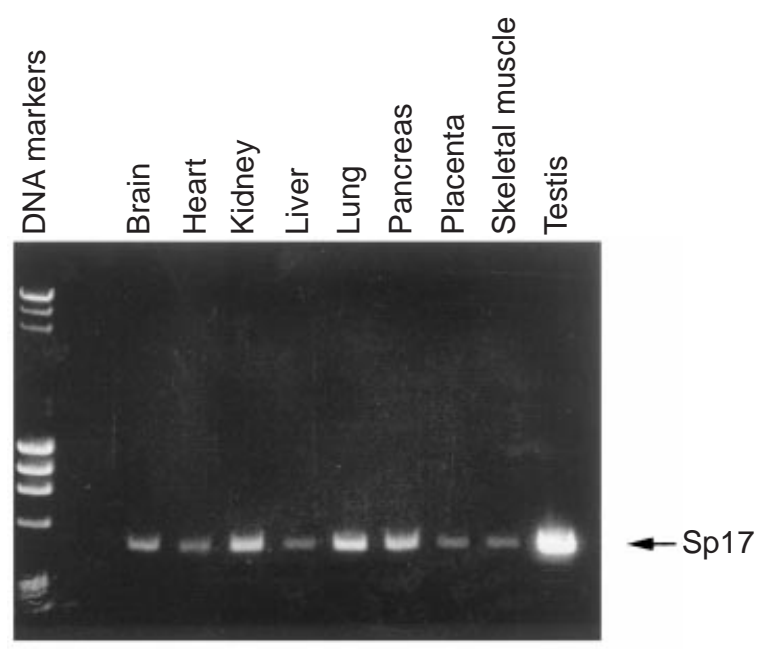

(b)

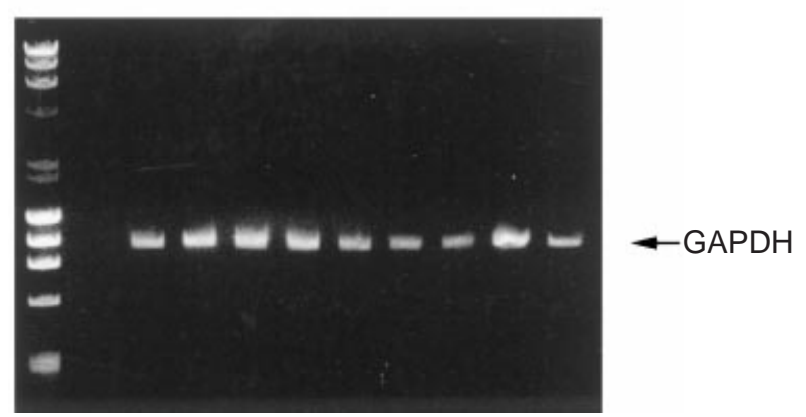

Fig. 3. Tissue distribution of human Sp17 transcripts. The presence of Sp17 transcripts in a variety of human tissues was determined by reverse transcription-polymerase chain reaction (RT-PCR), followed by agarose gel electrophoresis of the amplified products. (a) amplification using human Sp17-specific primers (5'-CCACCTGAGAAAAGTGATCC-3' and 5'-AAGGGTCTCTATAGATAGGC-3'). (b) Control amplifications using glyceraldehyde-3-phosphate dehydrogenase (GAPDH)-specific primers (5'-TGAAGGTCGGAGTCAACGGATTTGGT-3' and 5'-CATGTGGGCCATGAGGTCCACCAC- $3^{\prime}$ ) to ensure integrity of CDNA samples and equivalence of gel loading.

Sp17 transcripts of the predicted size were consistently detected in all human tissues examined, but in significantly lower amounts than in testis (Fig. 3). This was not due to genomic or other SP17 DNA contamination, as the PCR primers used span the last intron, and PCR amplification of the RNA templates without reverse transcription did not generate a PCR product. Comparable studies using CDNA from a range of macaque and rat tissues (data not shown) confirmed the widespread expression of Sp17 in somatic tissues; again expression was much lower than in testis.

Interrogation of sequence databases with the human Sp17 cDNA sequence has revealed the presence of a human, intron-less, Sp17-related gene, exhibiting $76 \%$ overall nucleotide sequence identity with the authentic human Sp17 transcript, but possessing many termination codons in all three reading frames. It was therefore important to establish whether this Sp17 pseudogene is expressed and, if so, whether it represents the low expression of transcripts seen in somatic tissues. With this in mind, PCR reactions were performed on human and macaque testis cDNA and genomic DNA, as well as cDNAs from a range of macaque tissues, using an Sp17 pseudogene-specific reverse PCR primer (5'-GTTCAGCCATGAGCCAAAATG$\left.3^{\prime}\right)$. The presence of an Sp17 pseudogene was confirmed in human as well as macaque genomic DNA, but no PCR products were obtained from any of the cDNAs tested, indicating that the Sp17 pseudogene is not expressed. Indeed, direct sequence analysis of the Sp17 PCR product originally detected in spleen confirmed that it represented expression of the authentic Sp17 gene, rather than the pseudogene.

The low expression of Sp17 transcripts in a wide range of human (Fig. 3), macaque and rat tissues is consistent with previous data in mice (Wen et al., 2001), but is apparently in disagreement with previously reported data in humans (Lim et al., 2001). However, in the last study, which used a similar RT-PCR-based approach, the amount of amplified PCR product obtained with human testis RNA was very low compared with that obtained in the present study, precluding the detection of the much lower amounts observed in the present study in somatic tissues. This finding is probably attributable to the inappropriate use of random primers rather than oligo-dT, by Lim and colleagues, when reverse transcribing relatively short RNA transcripts.

\section{Developmental regulation of Sp17 gene expression in rat testis}

Given the clear disparity in the amount of Sp17 transcripts in the adult testis, compared with somatic tissues, it was of interest to establish precisely when during spermatogenesis abundant transcription of Sp17 occurs. This is achieved by RT-PCR analysis of RNA from prepubertal animals. The use of such animals enables appearance of a specific transcript to be correlated with the latest differentiating spermatogenic cell type present at each post-partum time point. Such a study is practical only in a rodent model system owing to tissue availability. Total RNA was therefore extracted from a developmental series of prepubertal rat testes (days 1-44 after birth) and the amount of Sp17 transcripts was determined semi-quantitatively by RT-PCR using primers based on the rat Sp17 cDNA sequence (Fig. 4a). Rat Sp17 transcripts were readily detected from day 19 post partum onwards, correlating with the first appearance of pachytene spermatocytes (Fig. 4b). However, longer photographic exposure of the ethidium bromide stained gel (data not shown) demonstrated extremely low amounts of Sp17 transcripts at all earlier stages (days 1-13 after birth), implying some limited expression in testicular somatic cells. Several sperm-specific proteins are developmentally regulated in the testis, and transcription of their genes is 'switched on' peri- or post-meiosis (for example, fertilin $\beta$, tMDC I, 2BI). The very marked increase in Sp17 
(a)

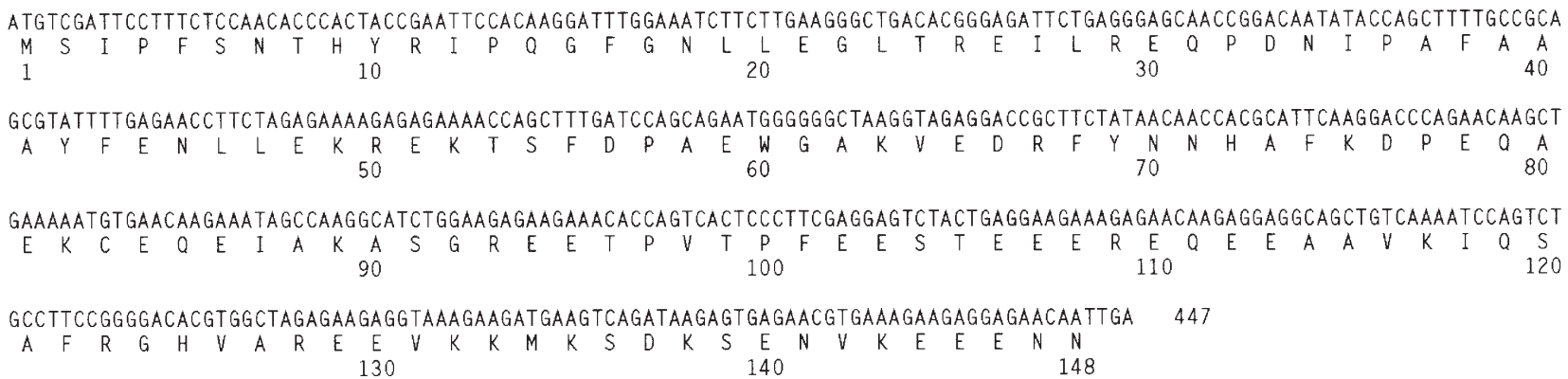

(b)
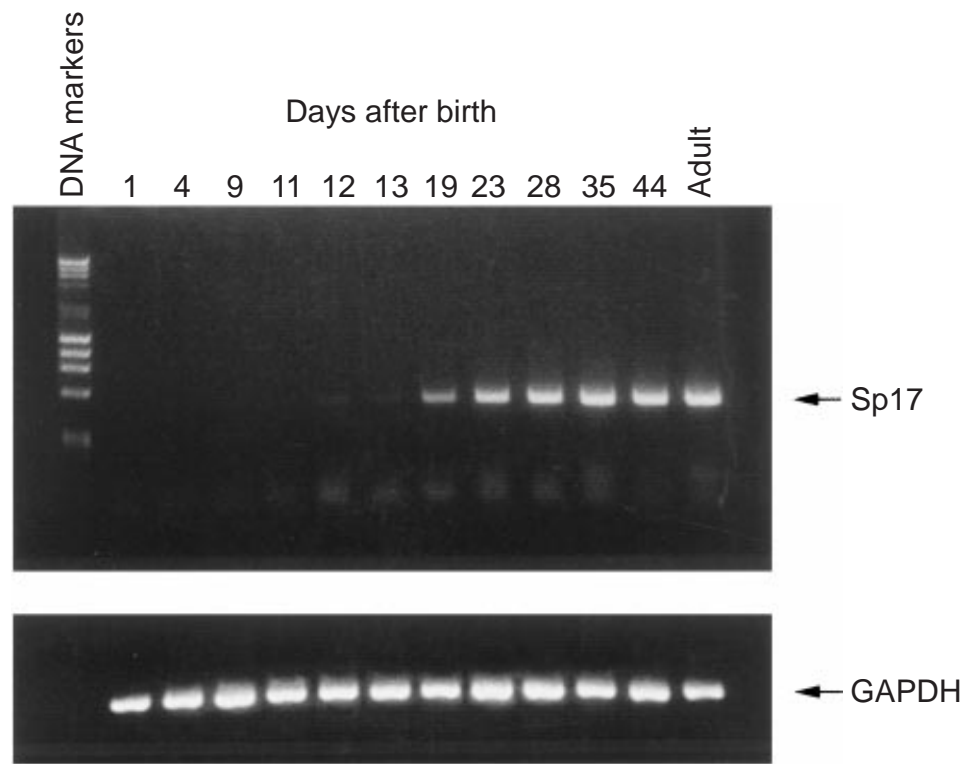

Fig. 4. Developmental regulation of Sp17 gene expression in rat testes. The entire coding region of rat Sp17 mRNA was amplified by reverse transcription-polymerase chain reaction (RT-PCR) using flanking primers (5'-AGGCAATTCTTTCCGAGGAG-3' and 5'GGGTAAAACCTGTGGTCTCA-3') based on the published mouse sequence. (a) The amplified product was cloned and sequenced on both DNA strands (accession number: AJ131888). (b) Sp17-specific primers designed using this rat sequence were then used to determine the presence of Sp17 transcripts by RT-PCR, in testes from prepubertal rats (upper panel); parallel control amplifications (lower panel) were also carried out using glyceraldehyde-3-phosphate dehydrogenase (GAPDH)-specific primers to ensure integrity of cDNA samples and equivalence of gel loading.

transcription from day 19 also indicates that it plays an important role in sperm function.

\section{Discussion}

Sp17 was originally detected in spermatozoa and proposed to be a zona pellucida binding protein. However, data supporting such a role are restricted to the ability of Sp17 to bind complex carbohydrates in vitro, a function attributable to the two conserved heparin-binding motifs present in the protein (Wen et al., 2001). Indeed, although in vitro fertilization is inhibited by antiserum against the RSA family of rabbit sperm proteins, this family contains antigens in addition to Sp17 (O'Rand 1981; O'Rand et al.,1984). Hence, there is no direct evidence that Sp17-specific antiserum alone inhibits sperm-zona pellucida interactions. Furthermore, localization of $\mathrm{Sp} 17$ within the tail regions of spermatozoa (Richardson et al., 1994; Kong et al., 1995; Adoyo et al., 1997) implies alternative or additional roles for this protein; this view is supported further by the present observation of transcripts for Sp17 in a wide range of tissues from rats, macaques and humans, albeit at significantly lower amounts than in the testes.

In seeking an alternative function for Sp17, the extremely high sequence conservation among mammalian species, particularly residues $1-74$, seems highly indicative of functional importance. Indeed 69 of these 74 residues are invariant in human, macaque, baboon, sheep, rabbit, rat and mouse Sp17 (Fig. 5). It is therefore interesting to note that whereas mouse recombinant full-length Sp17, and a truncated protein representing residues 61 to the C-terminal end, bound ${ }^{125}$ I-labelled heparin-albumin in vitro, a truncated protein corresponding to the first 60 amino acid residues showed no binding activity (Wen et al., 2001). This 
Consensus

Human Sp17

Macaque Sp17

Baboon Sp17

Sheep Sp17

Rabbit Sp17

Rat Sp17

Mouse Sp17
MSI - FSNTHYRI PQGFGNLLEGLTREILREQPDNIPAFAAAYFE - LLEKREKT - FDPAEWG-KV - DRFYNNHAF- - E

MSIPFSNTHYRI PQGFGNLLEGLTRE I LREQPDNIPAFAAAYFESLLEKREKTNFDPAEWGSKVEDRFYNNHAFEEQE MSIPFSNTHYRI PQGFGNLLEGLTREI LREQPDNI PAFAAAYFESLLEKREKTNFDPAEWGSKVEDRFYNNHAFEEQE MS I PFSNTHYRI PQGFGNLLEGLTREI LREQPDN I PAFAAAYFESLLEKREKTNFDPAEWGSKVEDRFYNNHAFEEQE MS I SFSNTHYRI PQGFGNLLEGLTREI LREQPDNI PAFAAAYFENLLEKREKTSFDPAEWGAKVDDRFYNNHAFKEQE MS I PFSNTHYRI PQGFGNLLEGLTREI LREQPDNI PAFAAAYFENLLEKREKTNFDPAEWGAKVDDRFYNNHAFQEHE MS I PFSNTHYRI PQGFGNLLEGLTRE I LREQPDN I PAFAAAYFENLLEKREKTSFDPAEWGAKVEDRFYNNHAFKDPE MS I PFSNTHYRI PQGFGNLLEGLTREI LREQPDNIPAFAAAYFENLLEKREKTSFDPAEWGAKVEDRFYNNHAFKEQE

$$
\begin{aligned}
& \text { - -EK- - - - - - - - - - - - - - - - - - } \\
& \text { PPEKSDPKQEESQISGKEEETSVT I LDSSEEDKEK-EEVAAVKI QAAFRGH I AREEAKKMKTNSLQNEEKEENK. } \\
& \text { PPEKSDPKQEESQIPGKEEEASVTI LDSSEEDKEK-EEVAAVKI QAAFRGHVAREEVKKMKTDSLQNEEKEENK. } \\
& \text { PPEKSDPKQEESQVSGKEEETSVTI LDSSEEDKEK - EEVAAVKI QAAFRGHVAREEVKKMKTDSLQNEEKEENSEDTGFTSRTHEK. } \\
& \text { SPEKHEPGKENSQTSVKEK - - - TALESPEGDKDM-EENAALKIQAAFRGHLAREEVKKMKSIDLEEEKTEENK. } \\
& \text { S-EKCEAE-EKSQ-SVTEEETPVLTID-SEDDKDK-EEMAALKI QAAFRGHLAREDVKKIRTNKAEEE-TEENN. } \\
& \text { QAEKCE - - QE I AKASGREE - TPVTPFEESTEEEREQEE - AAVKI QSAFRGHVAREEVKKMKSDKSENVKEEENN. } \\
& \text { QVEKCE - - QELAKSSGREE - TPVTPFEESTEEEREQEEAAALKI QSLFRGHVAREEVKKMKSDKNENLKEEADN. }
\end{aligned}
$$

Fig. 5. Amino acid sequence alignment of Sp17 from a range of mammalian species. Human and rat Sp17 sequences were determined in the present study. Other sequences were obtained from sequence databases: macaque (Macaca fascicularis; AF005551), baboon (Papio hamadryas; U75209), sheep (Ovis aries; AF179926), rabbit (Oryctolagus cuniculus; Z20655) and mouse (Mus musculus; Z46299).

finding implies that the heparin-binding motifs implicated in zona pellucida binding are likely to be located in the C-terminal half of the protein and that the highly conserved $\mathrm{N}$-terminal region serves some alternative function.

In attempting to establish a function for the extremely conserved N-terminal domain of Sp17, it is pertinent to note that this region contains a motif that is very similar to the $\mathrm{N}$-terminal sequence of PKA regulatory subunit II (RII; see Fig. 6). This region of RII contains the dimerization domain that is responsible for interaction between individual RII subunits, a prerequisite for binding to A kinase anchoring proteins (AKAPs).

AKAPs represent a family of sequence-unrelated proteins classified solely by their ability to bind to PKA in vitro. Studies using solution NMR structural analysis have shown that a preformed hydrophobic groove on the X-type fourhelix bundle of the RII dimer interacts with the hydrophobic face of a 14-18 residue amphipathic helix of an AKAP (Newlon et al., 2001). Many AKAPs also possess targeting domains that mediate their attachment to the cytoskeleton, plasma membrane or intracellular organelles. Furthermore, some AKAPs (see Coghlan et al., 1995; Klauck et al., 1996; Shih et al., 1999) bind simultaneously to PKA and other signal transduction molecules such as protein kinase C, protein phosphatase I (PPI), phosphodiesterase, calcineurin (PP2B) and calmodulin, as well as some receptors and ion channels, leading to the hypothesis that AKAPs function as scaffolding molecules that co-ordinate the actions of several signalling proteins, all located within one cellular compartment.

All AKAPs, by definition, bind the RIl subunit of PKA in vitro, and some have been shown to bind RII in vivo.
However, the recent identification of other proteins, such as Sp17, with a similar AKAP-binding motif implies that some AKAPs bind to proteins other than RII. Indeed, three spermspecific, AKAP-binding proteins have been identified, namely ropporin (Fujita et al., 2000; Carr et al., 2001), AKAP-associated sperm protein (ASP: Carr et al., 2001; Anway et al., 2002) and CABYR (also called fibrousheathin II; Naaby-Hansen et al., 2002); all of these molecules are localized to the fibrous sheath of the sperm tail. Each of these proteins contains an AKAP-binding domain in its $\mathrm{N}$-terminal region (Fig. 6) and both ropporin and ASP associate with AKAP3 in vitro, in a manner analogous to that of RII (Carr et al., 2001). Furthermore, ropporin, ASP, CABYR, Sp17, AKAP3 (Mandal et al., 1999) and AKAP4 (Johnson et al., 1997) all co-localize to the sperm tail, although Sp17 and AKAP3 are additionally located within the sperm head (Vijayaraghavan et al., 1999). Such findings support the contention that proteins other than RII bind to the 'RII-binding motif' of some AKAPs, at least for these sperm-specific AKAPs.

A novel role for Sp17 in promoting heparin sulphatemediated adhesion of lymphoid cells has been proposed by Lacy and Sanderson (2001), who showed that Sp17 expressed on the surface of lymphoid-derived cells of a patient with plasma cell leukemia promotes cell-cell adhesion via interaction with the heparin sulphate chain of syndecan 1. Somewhat surprisingly, addition of recombinant soluble Sp17 appeared to enhance cell-cell interaction rather than act as a competitive inhibitor, as would be expected if the interaction was dependent on the binding of membrane-bound Sp17 on one cell to syndecan 1 heparin sulphate on the other cell. Furthermore, expression of Sp17 


\section{Consensus}

Human Sp17

Human PKA-RIl $\alpha$

Human PKA-RII $\beta$

Fugu hypothetical protein

Fugu hypothetical protein

Fugu hypothetical protein

Sea urchin sperm PKA-RII

Human ASP

Human ropporin

Human CABYR/FSII

C. elegans hypothetical protein

D. melanogaster PKA-RII

D. melanogaster protein
$I P-G L-E L L Q-F T-E V L R=Q P=D L-F A-Y F-L$

Accession No

MSIPFSNTHYRIPQ GFGNLLEG LTREILREOPDNIPAFAA Y FEESLLEKREK

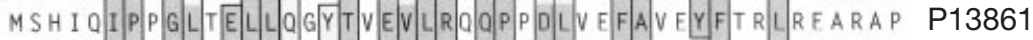

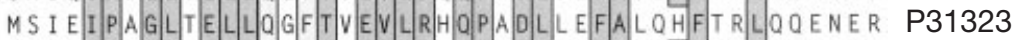

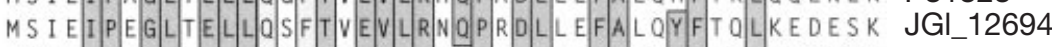

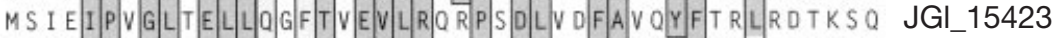

MTAVOIPVIGLKELLLQGYTVEVLRRRPP DLLVEFAVQHFTHIILSVQRN JGI_298

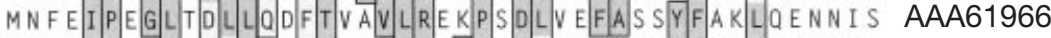

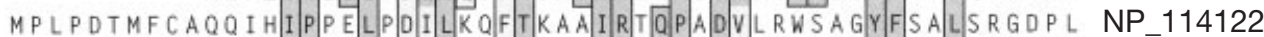

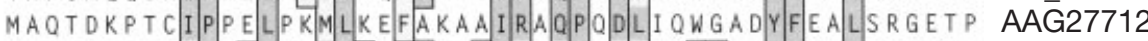

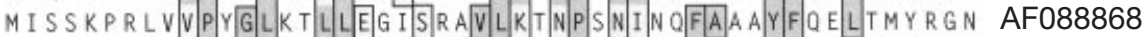

MDQRNKCFVP HDLRPILEA LAREVLLRSDPSDVAEFGHMFFDEYLKHRRE AAA83605

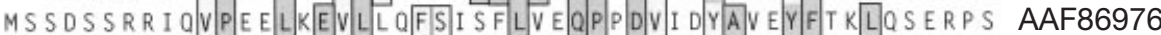

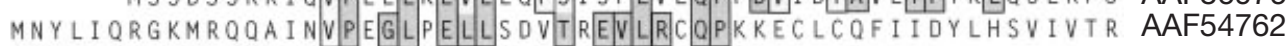

Fig. 6. Alignment of the N-terminal A-kinase anchoring protein (AKAP)-binding domains of the regulatory subunit and of a variety of proteins possessing a similar conserved binding motif. Highly conserved residues are boxed and highlighted in dark grey; conservative substitutions are boxed and highlighted in light grey. The source of each sequence (accession number) is indicated.

on the cell surface is not in keeping with the absence of a signal peptide in this protein. However, Chiriva-Internati et al. (2001) have demonstrated that surface expression of Sp17 in tumour cells and tumour cell lines is due to intracellular processing and presentation of Sp17 peptides in association with HLA class I molecules, rather than the protein naturally residing on the external plasma membrane. Furthermore, as high titre Sp17 antibodies are often detected in humans after vasectomy (Lea et al., 1997), with no evidence of impaired immunological function, it seems unlikely that Sp17 plays an important role in lymphoid cell adhesion events as proposed by Lacy and Sanderson (2001).

In conclusion, it has been proposed that the extremely high sequence conservation in the N-terminal half of Sp17, across a range of mammalian species, implies that this region is functionally very important. The fact that this is not the region of Sp17 that may be involved with spermegg interactions, the presence of Sp17 in somatic cells, and the obvious sequence homology within this region to the binding site of a range of AKAP ligands all strongly support the contention that the primary function of Sp17 is not zona pellucida binding. The diverse family of AKAPs derive their name from their ability to bind to the RII subunit of PKA in vitro. However, although such an interaction is physiologically relevant, at least for some AKAPs, it is becoming increasingly clear that in spermatozoa a number of alternative proteins are present that have been shown to bind to the 'RII-binding domain' of sperm-specific AKAPs. AKAPs are believed to function as scaffold proteins, bringing together a combination of cell signalling proteins, including PKA, thereby facilitating compartmentalized regulation. However, it now appears that several proteins including ropporin, ASP, CABYR and Sp17 have a similar AKAPbinding domain to PKA and therefore are likely to bind instead of PKA. In these cases, the term 'AKAP' may be inappropriate and misleading, the ability to bind PKA simply reflecting an in vitro property, rather than a functional association in vivo. Although an 'AKAP'-binding function for Sp17 has yet to be established, it is possible that
Sp17 plays a novel regulatory role in a PKA-independent 'AKAP' complex in both somatic and spermatogenic cells. However, it should be borne in mind that expression of Sp17 is much higher in the latter, raising the possibility that it may have a unique role in these highly specialized cells.

We thank Jennie Douthwaite for automated DNA sequence determination.

\section{References}

Adoyo PA, Lea IA, Richardson RT, Widgren EE and O'Rand MG (1997) Sequence and characterization of the sperm protein Sp17 from the baboon Molecular Reproduction and Development 47 66-71

Anway MD, Ravindranath N, Dym M and Griswold MD (2002) Identification of a murine testis complementary DNA encoding a homolog to human A-kinase anchoring protein-associated sperm protein Biology of Reproduction 66 1755-1761

Carr DW, Fujita A, Stentz CL, Liberty GA, Olson GE and Narumiya S (2001) Identification of sperm-specific proteins that interact with Akinase anchoring proteins in a manner similar to the type II regulatory subunit of PKA Journal of Biological Chemistry 27617 332-17 338

Chiriva-Internati M, Wang Z, Xue Y, Bumm K, Hahn AB and Lim SH (2001) Sperm protein 17 (Sp17) in multiple myeloma: opportunity for myelomaspecific donor $\mathrm{T}$ cell infusion to enhance graft-versus-myeloma effect without increasing graft-versus-host disease risk European Journal of Immunology 31 2277-2283

Chiriva-Internati M, Wang Z, Salati E, Timmins P and Lim SH (2002) Tumor vaccine for ovarian carcinoma targeting sperm protein 17 Cancer $\mathbf{9 4}$ 2447-2453

Coghlan VM, Perrino BA, Howard M, Langeberg LK, Hicks JB, Gallatin WM and Scott JD (1995) Association of protein kinase A and protein phosphatase 2B with a common anchoring protein Science $\mathbf{2 6 7}$ 108-112

Frayne J, Jury JA, Barker HL and Hall L (1997) Rat MDC family of proteins: sequence analysis, tissue distribution, and expression in prepubertal and adult rat testis Molecular Reproduction and Development 48 159-167

Fujita A, Nakamura K, Kato T, Watanabe N, Ishizaki T, Kimura K, Mizoguchi A and Narumiya S (2000) Ropporin, a sperm-specific binding protein of rhophilin, that is localized in the fibrous sheath of sperm flagella Journal of Cell Science 113 103-112

Johnson LR, Foster JA, Haig-Ladewig L, VanScoy H, Rubin CS, Moss SB and Gerton GL (1997) Assembly of AKAP82, a protein kinase A anchor protein, into the fibrous sheath of mouse sperm Developmental Biology $192340-350$ 
Klauck TM, Faux MC, Labudda K, Langeberg LK, Jaken S and Scott JD (1996) Coordination of three signalling enzymes by AKAP79, a mammalian scaffold protein Science 271 1589-1592

Kong M, Richardson RT, Widgren EE and O'Rand MG (1995) Sequence and localization of the mouse sperm autoantigenic protein, Sp17 Biology of Reproduction 53 579-590

Lacy HM and Sanderson RD (2001) Sperm protein 17 is expressed on normal and malignant lymphocytes and promotes heparin sulfatemediated cell-cell adhesion Blood 98 2160-2165

Lea IA, Richardson RT, Widgren EE and O'Rand MG (1996) Cloning and sequencing of cDNAs encoding the human sperm protein, Sp17 Biochimica et Biophysica Acta 1307 263-266

Lea IA, Adoyo P and O'Rand MG (1997) Autoimmunogenicity of the human sperm protein Sp17 in vasectomized men and identification of linear B cell epitopes Fertility and Sterility 67 355-361

Lea IA, Kurth B and O'Rand MG (1998a) Immune response to immunization with sperm antigens in the macaque oviduct Biology of Reproduction 58 794-800

Lea IA, van Lierop MJC, Widgren EE, Grootenhuis A, Wen Y, van Duin M and $\mathbf{O}^{\prime}$ Rand MG (1998b) A chimeric sperm peptide induces antibodies and strain-specific reversible infertility in mice Biology of Reproduction 59 527-536

Lim SH, Wang Z, Chiriva-Internati M and Xue Y (2001) Sperm protein 17 is a novel cancer-testis antigen in multiple myeloma Blood 97 1508-1510

Mandal A, Naaby-Hansen S, Wolkowicz MJ et al. (1999) FSP95, a testisspecific 95-kilodalton fibrous sheath antigen that undergoes tyrosine phosphorylation in capacitated human spermatozoa Biology of Reproduction 61 1184-1197

Naaby-Hansen S, Mandal A, Wolkowicz MJ et al. (2002) CABYR, a novel calcium-binding tyrosine phosphorylation-regulated fibrous sheath protein involved in capacitation Developmental Biology 242 236-254

Newlon MG, Roy M, Morikis D, Carr DW, Westphal R, Scott JD and Jennings PA (2001) A novel mechanism of PKA anchoring revealed by solution structures of anchoring complexes EMBO Journal 20 1651-1662
Old LJ and Chen Y-T (1998) New paths in human cancer serology Journal of Experimental Medicine 187 1163-1167

O'Rand MG (1981) Inhibition of fertility and sperm-zona binding by antiserum to the rabbit sperm membrane autoantigen RSA-1 Biology of Reproduction 25 621-628

O'Rand MG, Irons GP and Porter JP (1984) Monoclonal antibodies to rabbit sperm autoantigens. I. Inhibition of in vitro fertilization and localization on the egg Biology of Reproduction 30 721-729

Richardson RT, Yamasaki N and O'Rand MG (1994) Sequence of a rabbit sperm zona pellucida binding protein and localization during the acrosome reaction Developmental Biology 165 688-701

Shih M, Lin F, Scott JD, Wang HY and Malbon CC (1999) Dynamic complexes of beta2-adrenergic receptors with protein kinases and phosphatases and the role of gravin Journal of Biological Chemistry $\mathbf{2 7 4}$ 1588-1595

Vijayaraghavan S, Liberty GA, Mohan J, Winfrey VP, Olson GE and Carr DW (1999) Isolation and molecular characterization of AKAP110, a novel, sperm-specific protein kinase A-anchoring protein Molecular Endocrinology 13 705-717

Wen Y, Richardson RT and O'Rand MG (1999) Processing of the sperm protein Sp17 during the acrosome reaction and characterization as a calmodulin binding protein Developmental Biology 206 113-122

Wen Y, Richardson RT, Widgren EE and O'Rand MG (2001) Characterization of Sp17: a ubiquitous three domain protein that binds heparin Biochemical Journal 357 25-31

Yamasaki N, Richardson RT and O'Rand MG (1995) Expression of the rabbit sperm protein Sp17 in Cos cells and interaction of recombinant Sp17 with the rabbit zona pellucida Molecular Reproduction and Development 40 48-55

Received 18 July 2002.

First decision 23 August 2002.

Revised manuscript received 3 September 2002.

Accepted 3 September 2002. 